\title{
INTERVENÇÕES NO ESCOLAR: \\ PROBLEMÁTICAS DA INCLUSÃO
}

\author{
Ana Beatriz Coutinho Lerner \\ Daniele Silva Caitano \\ Isabel Correa Netto Cavalcanti
}

Nas últimas décadas, os avanços nas políticas públicas trouxeram a questão da diversidade para o centro do debate educacional. $\bigcirc$ movimento em favor da inclusão dos diferentes é fruto de reivindicações políticas e sociais sobre igualdade de direitos e cidadania. No que concerne ao âmbito da saúde mental, esse movimento ensejou o questionamento de uma série de dispositivos de tratamento que se sustentavam sobre uma lógica da segregação: leprosários, asilos, manicômios e, mais recentemente, os hospitais psiquiátricos. Podemos afirmar que o mote do movimento antimanicomial foi a humanização das relações entre sujeitos, sociedade e instituições e a decorrente construção de espaços de articulação dos excluídos no tecido social (Coutinho e Aversa, 1997).

No que tange à infância, a escola configura-se como um espaço privilegiado de circulação e pertencimento social e não tardou para que os princípios da reforma antipsiquiátrica chegassem às escolas e produzissem seus primeiros abalos.

Historicamente, a escola conservou-se como uma instituição destinada para alguns e não para todos. Diversos autores apontam a exclusão como traço estrutural na constituição das instituições educativas e destacam cortes históricos que produziram rearranjos dos grupos de incluídos e excluídos da escola, sem nunca, porém, alcançar uma condição de inclusão total das crianças que dela necessitavam.

O direito à instrução primária gratuita aos cidadãos brasileiros já estava prevista em lei desde a promulgação da Constituição Imperial, em I 824. Entretanto, no grupo seleto de indivíduos alçados à condição de cidadão não estavam incluídos os escravos - que, à época, representavam aproximadamente um quinto da população brasileira - e os índios, outra parcela significativa da população também excluída do direito à instrução por configurarem-se como "aptos a serem segregados em aldeamentos para efeito de civilização e catequese" (Cury, 2008, p.21 I).

Nesse período, a educação esteve voltada fundamentalmente para a aristocracia brasileira e baseava-se nos ideais europeus de educação. Somente a partir da República a escola passou a figurar como lócus privilegiado da promoção de igualdade social. Ainda assim, foram necessárias mais algumas décadas para que os movimentos sociais diversos resultassem em políticas de ampliação da oferta de escolarização para crianças em idade escolar.

Segundo Marques (2007), depois da década de 1920, período de confluência de movimentos sociais, culturais e políticos, podemos notar o "entusiasmo pela educação" e os efeitos dessas mudanças para ideário pedagógico. A proposição da Escola Nova surge na esteira dos movimentos de democratização da escola brasileira e de responsabilização 
do Estado pela educação, o que contribuiu para o a regulamentação do ensino básico obrigatório de quatro anos, em 1961, e sua ampliação para oito anos em 1971.

Para Patto (2005), este projeto igualitário encontrou limitações pela forma como as escolas foram constituídas no Brasil. Segundo a autora, as escolas constituíram-se à luz da organização social vigente que desqualificava "os pobres, os não brancos, os contestadores e os portadores de alguma dificuldade física ou mental que prejudicasse a capacidade de trabalhar ou de conformar-se às regras sociais" (p. 10).

Em relação às crianças com necessidades especiais, o ritmo das mudanças foi ainda mais lento. Marques (2007) afirma que até meados do século XX poucos estabelecimentos educativos no Brasil acolhiam crianças com algum tipo de deficiência. Apenas no final de década de 1950, começaram a surgir estudos sobre a população excluída dos dispositivos sociais, o que impulsionou o lançamento de programas políticos destinados à população de educação especial. Exemplo disso foi a promulgação da Lei de Diretrizes e Bases da Educação Nacional, em 1961, que assegurou o direito ao atendimento educacional às pessoas com deficiência preferencialmente na rede regular de ensino. $\bigcirc$ uso do termo preferencialmente no texto da lei e outras medidas governamentais empreendidas à época, tais como a criação do Centro Nacional de Educação Especial, não efetivaram uma política pública de acesso universal à educação, contribuindo com a manutenção de dois sistemas de ensino paralelos e não complementares: um voltado aos alunos considerados normais e outro destinado à escolarização de estudantes com deficiência (Brasil, 2008).

Essa situação só foi modificada de fato em 2008, após a publicação do decreto de número 657//2008, que alterou a política de financiamento dos alunos matriculados na educação especial e estabeleceu que o atendimento educacional especializado ocorresse de forma complementar ou suplementar à escolarização regular, instituindo a necessidade de criação de práticas e dispositivos de apoio à inclusão escolar.

Em que pesem os esforços e os avanços conquistados na legislação escolar, os dados educacionais atuais apontam para a perpetuação das condições de exclusão historicamente forjadas no Brasil. Como afirma Dubet (2003, p.29), "quanto mais a escola intensifica seu raio de ação, mais ela exclui, apesar das políticas que visam atenuar esse fenômeno".

Dubet (2003) faz considerações importantes a respeito da escolarização na França que podem ser analisadas à luz da realidade educacional brasileira. Ele estabelece uma distinção entre desigualdade social e seus efeitos na escola e a exclusão escolar propriamente dita, ou seja, aquela operada pelo próprio funcionamento escolar. Nos debates sobre inclusão/exclusão, essa distinção remete às condições de reprodução da desigualdade vigente, mas também de produção de exclusão no interior das escolas.

Por uma perspectiva sociológica, o autor demonstra o limite da crença de que o "desenvolvimento da oferta escolar é um fator gerador de igualdade de oportunidade e de justiça" (Dubet, 2003). A massificação escolar não reduz as desigualdades, pois o próprio sistema escolar atua seletivamente de forma a "encaminhar os alunos mais fracos para as trajetórias menos qualificadas, o que, por sua vez, aumenta suas chances de desemprego e precariedade" (p.35).

Ao analisar os mecanismos excludentes do funcionamento escolar, o autor destaca uma tensão fundamental: apesar de postular a igualdade de todos, a escola é 
meritocrática, ordena, hierarquiza e classifica os sujeitos em função de seus méritos, responsabilizando-os por seus sucessos e fracassos. Conclui que:

A exclusão escolar é o resultado "normal" da extensão de uma escola democrática de massa que afirma, ao mesmo tempo, a igualdade dos indivíduos e a desigualdade de seus desempenhos. Nesse sentido, a escola integra mais e exclui mais do que antes, apesar de seus princípios e de suas ideologias, e funciona cada vez mais como o mercado que é, em sua própria lógica, o princípio básico da integração e da exclusão (Dubet, 2003, p.44).

A partir de outra fundamentação teórica, a psicanalítica, Kupfer e Petri (2000) afirmam que o discurso social na modernidade encaminhou a infância para a escola e criou uma discursividade em que ganham existência as categorias de crianças escolarizáveis e não escolarizáveis. De acordo com as autoras, "quando a escola se instala, instala-se, no mesmo golpe, a criança especial. Cria-se uma categoria que não tinha existência independente, mas que passa a existir junto com a escola" (p. I | 0 ).

Por meio dessa operação discursiva, engendra-se a criação de um novo objeto, as crianças especiais. Paradoxalmente, a existência de crianças diferentes, em função de suas deficiências ou funcionamento atípico, e o tratamento historicamente destinado a elas em uma sociedade normatizadora colaborou para a definição dos contornos do grupo de crianças consideradas escolarizáveis, servindo à garantia de constituição da própria escola.

A criação da escola contorna então um Real e passa a dizê-lo. E, ao contornar o Real pode passar a dizer o que ela não é, ou quem não são suas crianças. A escola encontra seus pontos de referência identitários nesse contorno e, o expelido pela instalação do contorno ajuda a defini-la. Assim, a reabsorção do que ela não é ameaça a sua consolidação como instituição (Kupfer e Petri, 2000, p. I 12).

Para termos uma amostra disso, basta nos atentarmos aos deslizamentos terminológicos sofridos pela população de crianças alvo das políticas educacionais especiais: excepcionais, deficientes, especiais, portadores necessidades educativas especiais, crianças de inclusão e, mais recentemente, crianças-laudo. Ainda que consideremos que a escolha desses termos produza diferentes efeitos subjetivos naqueles assim nomeados e que essas mudanças reflitam o desejo de deslocar o foco da questão exclusivamente do indivíduo para as instituições que circunscrevem lugares sociais, a situação mostra-se bastante complexa, na medida em que novos nomes podem esconder velhas práticas.

Voltolini (2004, p.99) afirma que "não existe um grupo que inclua a todos, na medida em que um grupo só se constitui quando marca uma diferença com aquilo que não pertence ao grupo". Para ele, "não há como agregar sem segregar. Isto torna qualquer ideia de política inclusiva, uma vez que seu princípio é agregar quem está segregado, um movimento impossível, dado seu caráter de infinitude." Infinito, posto que impossível de 
concluir, porém realizável ainda que não totalmente. Destacar os mecanismos de segregação como traço estrutural dos grupos e, por conseguinte, da escola, não implica em afirmar a inviabilidade da inclusão, mas atentar para as condições necessárias de enfrentamento e manejo das dificuldades inerentes ao processo: "não se pode esperar emancipar-se deles [dos efeitos de estrutura]. O que não significa resignar-se a eles, mas, ao contrário, considerá-los como vicissitudes e manejá-los tais como aparecem em cada situação singular" (Voltolini, 2004, p. I00). Além disso, implica em abordar a questão da inclusão do ponto de vista não apenas da diferença propriamente dita, mas da desigualdade impingida por um grupo majoritário àqueles considerados menos aptos a habitarem determinados espaços.

Lajonquière (20l I) atenta para os riscos das ilusões psicopedagógicas que se revestem de palavras de ordem ao afirmar que a exclusão escolar, antes dirimida em grande escala, hoje "processa-se nos pequenos detalhes psico-pato-pedagógicos da vida cotidiana". O autor afirma ainda que a educação das crianças diferentes ou:

[...] a satisfação de suas necessidades educativas especiais converteu-se em uma conquista sem descanso, em uma missão civilizacional sem pausa, sem dúvidas e sem imprevistos - toda ela necessária. Porém, cada vez que parece se ganhar um centímetro à selvageria, ela - assim como o quero-quero - teima em piar em um outro lugar (Lajonquière, 200 I, p.52).

É necessário fazer a crítica da ilusão psicopedagógica que subverte o discurso inclusivo de direção ético-política a ser perseguida para um imperativo a ser cumprido a qualquer custo e de qualquer maneira por meio de medidas técnicas e administrativas. No caso específico da inclusão escolar de crianças autistas e psicóticas, esta situação se complexifica quando se espera que uma criança refratária ao laço social se comporte, aprenda e interaja como as outras crianças.

É de fundamental importância afirmar a legitimidade das políticas públicas voltadas à inclusão e necessário alargar as fronteiras da escola, operando sobre sua lógica segregacionista para que ela possa acolher o maior número de crianças possível, empurrando "a linha que demarca os de dentro e os de fora para outro lugar" (Voltolini, 2004, p.99).

Porém, desejamos enfatizar também a inevitabilidade da tensão decorrente dos processos de inclusão para desconstruir um ideal de harmonização que se instala no cenário educativo produzindo sofrimento para aqueles que vivem as dificuldades de implementação deste projeto ético-político. Esse ponto diz respeito às condições subjetivas da inclusão, ao que está para além das legislações e procedimentos que dão sustentação às práticas inclusivas.

Nesse sentido, consideramos que o alargamento das fronteiras da escola e o encontro com a diferença têm se constituído como um importante desafio no cotidiano escolar e têm produzido interessantes invenções que apontam para a construção de um espaço que efetivamente possa acolher e transmitir algo a todas as crianças.

Com o intuito de trabalhar nessa direção e formar profissionais de psicologia para atuar na realidade complexa em que vivemos, o Serviço de Psicologia Escolar do Instituto de Psicologia da USP oferece, desde 20 I I, uma modalidade de estágio aos alunos do 
curso de Psicologia que consiste no acompanhamento da escolarização de crianças com transtornos psíquicos em processo de inclusão na escola regular. Este trabalho, de franca inspiração na prática do Acompanhamento Terapêutico (AT), guarda especificidades que dizem respeito ao solo institucional em que é realizado: a escola, com seus determinantes sociais, sua política discursiva, sua lógica particular de funcionamento e seus lugares instituídos e instituintes que devem ser considerados no desenho de nossa prática.

Compartilhamos da perspectiva segundo a qual educar é introduzir a criança em um mundo compartilhado que antecede seu nascimento. É transmitir marcas simbólicas de pertencimento a uma determinada cultura ou lugar, colocando à disposição da criança os objetos do conhecimento para que possa construir um saber sobre si, sobre o outro e sobre seu lugar no mundo. "A educação é, e sempre foi, um componente inevitável da construção social e uma coprodutora de subjetividade. $\bigcirc$ tratamento institucional do enigma subjetivo em relação ao conhecimento é seu objeto, assim como o tecido do laço social é sua meta" (Frigério, 200 I , p. I 10). Para isso, o ensino de conteúdos pedagógicos é necessário, mas não suficiente.

Assim como o AT, o acompanhamento da escolarização é uma modalidade de trabaIho que se orienta "por uma ética que coloca a singularidade como guia, uma vez que o desejo é sempre singular" (Estevão e Metzger, 2015, p.73). Sem porém, recair na falsa dicotomia entre individual e coletivo, na medida em que, do ponto de vista psicanalítico, que orienta nosso trabalho, consideramos que é a partir do encontro com o outro, no social, que são tecidas as singularidades.

O acompanhamento escolar no paradigma da educação para todos é um trabalho que caminha na direção da construção do laço da criança com seus pares, os educadores e os objetos do conhecimento. Nossa hipótese é que experimentar novos enlaces com o conhecimento pode favorecer a construção de múltiplos sentidos para a experiência de ser aluno, impulsionar a participação nas atividades compartilhadas e a apropriação das regras que organizam o coletivo da escola.

De acordo com Sereno (2006), o acompanhante escolar desempenha algumas funções junto ao aluno. Sua presença na escola constitui-se como uma referência que sustenta para a criança os códigos (regras e comportamentos) que regem aquela instituição, ao mesmo tempo que dá lugar e voz aos seus interesses e modos de habitar o espaço escolar. Pode atuar como uma espécie de tradutor ou porta-voz da criança oferecendo sua escuta, a partir da transferência, e leituras sobre os comportamentos estranhos a partir da suposição de que o aluno é um sujeito que tem algo a dizer. Além disso, permite o exercício de um testemunho das situações cotidianas que o aluno vivencia na escola, atestando o valor de suas produções, conquistas e impasses.

Sobre o lugar de testemunha e de "secretário do alienado"' no trabalho junto à psicose, Estevão e Metzger (2015, p.76) afirmam que o acompanhante pode "presenciar e legitimar a experiência delirante vivida pelo psicótico, por meio da escuta," acompanhá-lo

I Proposição de Lacan (1955/1985), no Seminário 3: As psicoses, sobre a função do analista no tratamento da psicose. 
em suas incursões, auxiliando no trabalho necessário para que do delírio possa advir algum enlaçamento possível.

Contudo, a intervenção junto à criança é apenas uma parte do trabalho realizado pelo acompanhante. Há ainda outro importante campo de intervenção que implica em tomar a escola como uma rede discursiva que define lugares e constrói saberes sobre os alunos e o fazer educativo. Portanto, não se trata apenas de escutar as crianças em seus percalços e construções na escola, mas também de escutar a escola, tendo em vista a demanda que endereçam ao acompanhante escolar.

Muitas vezes, o campo educativo endereça aos profissionais de saúde pedidos relacionados à adequação da criança ao que se espera de um aluno padrão. Nesse pedido, nem sempre está contida a suposição de um saber no acompanhante para intervir na escola, propondo questionamentos e eventuais inflexões nas práticas pedagógicas. Oury ( 199|), ao discorrer sobre a formação dos profissionais que trabalham com a loucura, estabelece uma relação entre o tratamento e a escola, afirmando a necessidade de "uma espécie de coesão" entre os profissionais que atuam em ambas as instituições.

Quando uma criança é um "inadaptado escolar", sabe-se muito bem que é frequentemente a escola que esta inadaptada à criança. É sobre este pano de fundo que se deve retomar a questão, na maior parte das vezes ridícula, da integração. Integração para que? Se não se modifica o meio escolar, a intrusão de um psicótico, frequentemente só contribui para aumentar a desordem coletiva (Oury, 1991, p.43).

Como lembram Estevão e Metzger (20 I5), acolher a uma demanda é diferente de responder a ela: "acolher a demanda significa ir ao encontro do acompanhado e escutá-lo [...] supondo um sujeito do inconsciente e uma lógica oculta que opera e manifesta-se, ocasionalmente, em sonhos, atos falhos, sintomas, lapsos" (p.77). Essa lógica inconsciente se constrói a partir da inscrição do ser no social - não sendo seu atributo natural ou individual - e escutar não significa apenas ouvir a fala da pessoa e muito menos atender literalmente seu pedido, mas "fazê-lo falar daquilo que demanda". Ao escutar a fala do sujeito, a partir do lugar transferencial em que estamos situados, podemos localizar os significantes que se presentificam em seu discurso e compõem a trama de seu saber inconsciente, sustentar o enigma diante de situações em que somos convocados a dar respostas práticas e técnicas e caminhar na direção da construção de um saber-fazer mais autoral por parte de educador, em alguma medida, sempre inédito.

Nesse sentido, é importante que o acompanhante escute o discurso dos educadores e produza questões na escola que a faça sair do lugar, movimentar-se. A criança, como aluno da escola, mobiliza diariamente os profissionais envolvidos na tarefa de ensinar, e o trabalho do acompanhante deve se articular em rede com os profissionais da escola para criar espaços de interlocução em que os diversos olhares sobre a mesma criança possam coexistir, ampliando as possibilidades de intervenções e criações que visam à construção 
de um lugar de aluno a partir do encontro com o outro e os objetos do conhecimento disponibilizados pela escola.

É o que Kupfer e Bastos (2010) definem como a inclusão dos educadores com vistas ao engajamento da escola como uma instituição responsável em educar todas as crianças.

Para ilustrar a modalidade de estágio em acompanhamento escolar na inclusão proposto pelo Serviço de Psicologia Escolar, apresentaremos duas cenas de trabalho com algumas crianças e suas respectivas escolas para refletir sobre a função do acompanhante escolar e os efeitos subjetivantes da escola².

\section{QUEM DANÇA SEUS MALES ESPANTA}

Juliana, 6 anos, está no $2^{\circ}$ ano do Ensino Fundamental de uma EMEF e tem acompanhamento escolar há cerca de um ano. Entrou nesta EMEF na metade do ano, pois não estava bem adaptada à escola anterior, que contava com um método bastante tradicional de ensino. É uma das poucas crianças de sua turma com o processo de alfabetização bastante adiantado. Demonstra muito interesse pelas letras e nomes daqueles ao seu redor. Logo de início foi possível perceber a quantidade considerável de pessoas que ela conhecia e com as quais se comunicava pelos corredores da escola. Em sua sala de aula, interagia com vários colegas, ainda que com alguns atritos e desentendimentos.

Muitas vezes no cotidiano escolar, as crianças se irritavam com Juliana por rir em momentos inapropriados. Quando algum amigo estava levando bronca, caía na risada, sem notar se o outro ficava irritado ou chateado com a reação. Além disso, se pedia algo emprestado para um colega que se recusava a atendê-la, era comum disparar palavrões ou socos na pessoa. Essas são algumas situações que pedem mediação do adulto, pois mostram uma vontade e curiosidade dela em relação às outras crianças, e, ao mesmo tempo, formas de aproximação que afastavam seus colegas.

A dificuldade de Juliana reside em perceber os limites do outro e respeitar seu espaço. Isso produz certo distanciamento em seus colegas que, por vezes, recusam sua presença. "Posso brincar também?", dizia Juliana. "Não!", respondiam seus colegas. Não raro, chamavam-na de "esquisita", "estranha" ou louca.

Um dia na escola, os alunos do primeiro ano tiveram um horário livre dentro da sala de aula para brincar. Alguns meninos pegaram o rádio portátil e ligaram para escutar música. Ficaram por um tempo trocando de estação até que encontraram uma música pop cantada em inglês. Juliana, que estava um pouco distante deles, começou a cantar em um idioma inventado - que parecia imitar o inglês - e dançar. Os meninos olharam com uma cara de estranhamento diante daquela cena, censurando-a por cantar e dançar daquele jeito diferente.

Nesse momento, surgiu a interrogação por parte da acompanhante. Como intervir nesse contexto de estranhamento diante do inusitado de Juliana sem meramente

2 ○stágio foi realizado em duas escolas públicas da cidade de São Paulo, em 20I4, pelas alunas do curso de Psicologia Daniele S. Caitano e Isabel, coautoras desse capítulo juntamente com a psicóloga Ana Beatriz Coutinho Lerner, que supervisionou o estágio. 
condenar a atitude dos outros alunos? Como situar a intervenção fora do campo da moralização ou da denúncia de um comportamento preconceituoso ou excludente? A acompanhante começou a dançar junto com ela. Inventou uma dança um pouco engraçada e acompanhou os movimentos de Juliana ao som da música. Depois de algum tempo, os meninos pararam de encará-la e começaram a dançar também.

Ao analisarmos essa intervenção a posteriori no espaço da supervisão, consideramos que a sustentação em ato de um enlace com a criança, a partir do que ela manifestava de insólito, pode minimizar o impacto da presença desmesurada de Juliana na sala e propiciar pontos em comum que derivaram para uma brincadeira coletiva: uma dança possível entre vários. Queremos destacar a importância de escutar uma produção subjetiva da criança, sustentar o estranho que ela provoca no grupo sem reprimi-la ou discipliná-la para, depois, fazer uma oferta de laço que contenha a valorização dessa "pura singularidade" (Oury, 1991, p.48).

Oury ( 199 | ) situa um ponto em comum entre as práticas pedagógicas e as estratégias de tratamento da psicose que consiste no respeito ao outro, em uma dimensão ética:

A maneira de abordar o outro, a maneira de estar "com" o outro... sabe-se bem, o que é específico da psicose são as dificuldades, uma impossibilidade de "estar com" (no sentido de estar com o outro, poder respeitar o outro aí onde ele está), proveniente de uma confusão entre o mesmo e o outro. E para ter acesso a este fenômeno, é necessário ser capaz de aceder a um certo lugar, uma certa "paisagem", ser sensível ao pequeno detalhe, mesmo escondido, mesmo insólito, ser sensível à emergência, ser sensível "àquilo que tem pathos"” (p.45).

Alice é uma colega da sala de Juliana. As duas costumam brincar e brigar porque provocam uma à outra com tapas e xingamentos. Um dia, Juliana se aproximou de Alice e disse num tom desafiador: "E aí, playboy?!". Alice ficou brava com a abordagem e partiu na direção de Juliana com socos e pontapés. Juliana entrou na briga, bateu também e dava risada da situação, enquanto a acompanhante e a professora tentavam separar as meninas.

Na mesma semana, as duas começaram uma brincadeira com tapas e jogaram água uma na outra. A acompanhante ficou aflita e atenta, esperando novamente o momento de separá-las, caso fosse necessário, mas sustentando o risco necessário (de uma agressão e suas repercussões na escola) para que daquele encontro pudesse surgir um laço particular entre elas. Quando a acompanhante esboçou intervir na brincadeira, Juliana disse em alto e bom tom para Alice: "Você está sendo minha melhor amiga!".

3 Pathos ou path é uma palavra grega que significa paixão, excesso, catástrofe, passagem, passividade, sofrimento, assujeitamento, sentimento e ligação afetiva. 


\section{QUEM É ESSE MENINO?}

Lucas, 5 anos, frequenta uma EMEl na cidade de São Paulo e é acompanhado na escola há pouco mais de um ano. É o primeiro ano de Lucas na EMEl, depois de um longo período na creche. Essa transição foi permeada por conquistas e desafios, como aprender a comer sozinho e balizar suas aç̃es conforme as regras de convivência com o grupo.

Além de sua professora, Lucas tem sido regularmente acompanhado por uma Auxiliar de Vida Escolar (AVE), uma profissional contratada pela prefeitura e selecionada na própria comunidade para acompanhar os alunos que não têm autonomia e necessitam de apoio para alimentar-se, fazer a própria higiene e usufruir do espaço escolar.

O trabalho da AVE, que chamaremos de Célia, se faz de forma intensa. Ela passa bastante tempo sentada ao lado de Lucas para auxiliá-lo em suas atividades dentro e fora da sala. A partir das conversas com a equipe escolar, entendemos que ajudar Lucas e outros alunos "especiais" era a própria condição de existência da função de Célia nessa escola. Nesse sentido, tornava-se compreensível sua hesitação entre fazer algo pelo aluno (alimentá-lo, contê-lo ou limpá-lo) para aliviar o trabalho da professora e sustentar um tempo de desorganização necessário para que Lucas experimentasse suas possibilidades diante das tarefas propostas e pudesse fazê-las, eventualmente, com o apoio das outras crianças e profissionais da escola.

Víamos Célia premida entre a crença na condição especial, deficitária, de Lucas e o desejo de ensinar a ele os limites a que todos estavam submetidos na escola. Para ela, Lucas não podia ficar sozinho no recreio, não podia jogar areia ou pegar um livro fora de hora porque ele era uma criança como qualquer outra, mas precisava ser tutorado, alimentado e limpo pois era uma criança especial. Kupfer (2005) analisa esse paradoxo da inclusão:

Na defesa da inclusão escolar invoca-se, ora a igualdade de todas as crianças, ora sua diferença. Essa discussão chega à sala de aula, e diante dela a professora não sabe mais que lado escolher. Ora impõe regras para todas, o que torna inviável a presença daquela criança que não faz outra coisa a não ser balançar-se ritmicamente, ora afirma que devemos respeitas as diferenças e permite que Joãozinho rasgue todos os desenhos que faz, para a revolta geral da classe (p. 18).

Entendíamos que a intervenção da acompanhante escolar precisaria tocar a posição de Célia na relação com Lucas, mas como fazer isso? Como agir na tensão entre o coletivo da escola e o singular de Lucas, considerando que incluir não corresponde a tornar igual, no sentido de homogeneizar a partir de um critério de normalidade, nem tampouco manter-se igualmente diferente, já que, com a educação, pretendemos alçar construções que transformem, em alguma medida, todas as crianças? 
Vivíamos situações difíceis em que a acompanhante, por sua condição de êxtimo ${ }^{4}$, de elemento próximo, dentro, mas sem deixar de ser exterior, conseguia suportar a errância de Lucas e a não apropriação de interdições bastante básicas à convivência com o outro. Tal condição possibilitava que ela propusesse derivações para as estereotipias da criança, atribuísse sentidos possíveis a seus comportamentos e os compartilhasse com as outras crianças e os educadores. Sereno (2006) nos indica que a presença ativa do acompanhante na "escola pode favorecer novas possibilidades de sentido, articulação, encontro, o que pode implicar em um novo posicionamento da criança que aí está se constituindo". A partir de um investimento na subjetivação do aluno, jogar areia pode se tornar brincar com areia, manusear livros pode disparar o interesse pelas histórias, correr erraticamente pode virar uma brincadeira de pega-pega.

Certa vez, quando voltavam do parque externo, Lucas saiu correndo em direção ao portão da escola. A professora pediu, então, que dois colegas corressem atrás dele para trazê-lo de volta. Depois desse dia, João passou a buscar Lucas em vários momentos: quando corria em direção à cerca da escola, escapava para o pátio interno ou corria pelos corredores.

Essa busca por Lucas pareceu interessante na medida em que deslizou de um comportamento de vigilância para precaver-se de uma fuga para um movimento em que uma criança o enlaça e o convida para voltar para o campo do coletivo. Em uma dessas situações no parque interno, João segurou Lucas pela mão. A acompanhante, juntamente com uma colega de classe que estava por perto, sugeriu que brincassem de roda. Todos deram as mãos e começaram a cantar uma ciranda. Após terem rodado um pouco, Lucas soltou-se do colega e colocou a mão na boca, interrompendo a brincadeira. Esse movimento de levar a mão à boca era repetido todas as vezes em que Lucas vivia uma angústia decorrente do encontro com o outro. Nossa hipótese é que a experiência prazerosa da brincadeira compartilhada com o outro produziu uma excitação de difícil elaboração que fez com que ele buscasse refúgio em seu próprio corpo. Outros momentos de brincadeira aconteceram com a proximidade dos colegas. As crianças quebraram a impressão de que era melhor ficar longe de Lucas, já que ele não gosta muito de contato, passaram a topar os encontros e Célia foi aguentando mais o tempo necessário para que Lucas incorporasse determinadas regras. Ao longo desse processo, alguns momentos de interlocução com os educadores foram propostos pela acompanhante. Nessas ocasiões, oferecíamos outras leituras possíveis para os comportamentos de Lucas, construíamos conjuntamente algumas intervenções e mostrávamo-nos parceiras para correr os riscos de mudar determinados modos de abordá-lo na escola. Algumas vezes, apontávamos os efeitos de tomá-lo como objeto de cuidados e os perigos da imposição da vontade de ordem à aparente desordem que ele introduzia no contexto escolar. $\bigcirc$ excesso de contenção e disciplina não deixava o intervalo necessário para que algo do sujeito pudesse advir.

4 Êxtimo é um termo utilizado por Lacan para definir uma "intimidade exterior". Pode ser considerado em diferentes acepções da palavra: para apontar que o mais íntimo do sujeito está relacionado ao exterior e falar de uma função daquele que olha de fora para bem ver, distância que permite acessar a dimensão inconsciente das produções do sujeito. 
Uma cena que ilustra esses momentos de tensão deu-se na sala de leitura, quando Lucas escolheu algumas revistas das quais parecia gostar bastante. No início de sua escolarização, Lucas relacionava-se com os objetos escolares de maneira bastante errática, interessando-se quase nada por eles, a não ser para manuseá-los de forma mecânica ou arremessá-los para todos os lados. Com o passar do tempo, pudemos observar que deixou de jogar as revistas no chão, passou a escolher sempre as mesmas e a ordená-las na estante. Também passou a ser frequente o ato de levar as revistas para as mesas, momentos em que a acompanhante tentava enlaçar seus colegas em uma leitura compartilhada ou ao menos chamar a atenção de Lucas para as escolhas dos outros alunos. Em um desses dias, ao final da atividade de leitura, Lucas resistiu em abandonar a sala e permaneceu próximo a estante de revistas, mudando-as novamente de lugar. Parecia desejoso de continuar com suas "leituras", mas Célia tomou-o pelo braço, dizendo firmemente que era hora de sair da sala.

Por um lado, compreendemos que essa maneira de lidar com o aluno é importante para resguardar o funcionamento escolar, a rotina e a convivência entre as várias crianças e adultos. A ênfase dada à importância do não, nesse caso, não poder permanecer na sala após o fim da atividade, pode ser lida como um modo de auxiliar a criança a incorporar as interdições inerentes ao laço social. De acordo com a escola, essa abordagem foi eficaz, por exemplo, na retirada das fraldas de Lucas. Por outro lado, retira-lo da sala à força, silencia a pergunta sobre o motivo que o estava mantendo lá. Entendemos que a possibilidade de construção dessa pergunta que detém a ação imediata do educador e o faz interrogar-se sobre o aluno e sobre seu ato é o objetivo e a grande responsabilidade do acompanhante escolar.

Algumas semanas depois, a professora propõe uma brincadeira de corre cotia. Uma aluna cochicha no ouvido da acompanhante: "você sabia que o Lucas nunca foi escolhido?". Ela se volta para Victor, outro aluno da sala, e fala: "Não é, Victor, que o Lucas nunca foi escolhido?". Victor pensa por alguns instantes e concorda com a colega. A acompanhante pergunta se eles imaginam o porquê disso, e eles ficam pensativos. Depois de um tempo, a aluna pergunta para a acompanhante escolar: "Afinal, quem é ele?".

\section{CONSIDERAÇÕES FINAIS: O ESTRANGEIRO NA ESCOLA}

A Educação Inclusiva tem como proposta o acolhimento das diferenças e a consideração das peculiaridades de cada criança em seu processo de escolarização. A aprendizagem, porém, sofre diretamente os efeitos dos entraves vividos na constituição psíquica das crianças psicóticas e autistas, o que torna ainda mais difícil sua inclusão na escola. A presença de crianças com dificuldades no laço social na escola evidencia a ancoragem dos processos de aprendizagem nas relações que estabelecemos com os outros ao longo de nossa história, o que se revela um desafio para a Educação tradicional.

Lucas e Juliana, como tantos outros diferentes, despertam nos demais alunos perguntas sobre seu modo de ser: por que Lucas não fala? Por que Juliana bate e xinga? Essas e outras questões, muitas vezes, dirigem-se às acompanhantes escolares e revelam a importância de constituirmos um trabalho de inclusão que vá além de tolerar o que há de inquietante no outro ou fazer semblante de aceitação do lugar do diferente. 
Na perspectiva em que trabalhamos, as intervenções no Acompanhamento Escolar mantêm no horizonte a possibilidade de encontro com o outro naquilo que o destaca de um jeito singular, possibilitando que o que é visto no outro como assustador e estranho possa retornar ao sujeito como questão sobre ele mesmo. $\bigcirc$ reconhecimento da face estrangeira de nós mesmos abre novas possibilidades de conviver com o diferente.

É partir do momento em que o cidadão-indivíduo cessa de se considerar unido e glorioso para descobrir as suas incoerências e os seus abismos, em suma, as suas estranhezas, que a questão volta a se colocar: não mais a da acolhida do estrangeiro no interior de um sistema que o anula, mas a da coabitação desses estrangeiros que todos reconhecemos ser (Kristeva, 1994, p. I0).

Ao contribuirmos para que ocorram momentos de encontros potentes e experiências enriquecedoras na relação com o conhecimento, ampliamos as possibilidades de essas crianças construírem um dizer sobre si e de serem acolhidas a partir de sua singularidade. Tal intervenção produz efeitos de reverberação também nos educadores que se indagam sobre potencialidades dos alunos que ainda não haviam se expressado na escola. Sustentamos uma interlocução que deixa em aberto as perguntas: "Quem é esse aluno?", "Quem sou eu como professor?", "'O que é aprender?". No espaço vazio deixado por essas perguntas um novo caminho de inclusão poderá se construir. 


\section{REFERÊNCIAS BIBLIOGRÁFICAS}

Bastos, M. B., \& Kupfer, M. C. M. (2010). A escuta de professores no trabalho de inclusão escolar de crianças psicóticas e autistas. Estilos clin. [on-line]. I5(I), I I6- 125.

Brasil. Secretaria de Educação Especial. (2008a). Política Nacional de Educação Especial na Perspectiva da Educação Inclusiva. Brasília. [Documento elaborado pelo Grupo de Trabalho nomeado pela portaria n. 555/2007, prorrogada pela portaria n. 948/2007, entregue ao ministro da Educação em 7 de janeiro de 2008]. Recuperado em março, 2017, de http:// portal.mec.gov.br/arquivos/pdf/politicaeducespecial.pdf.

Coutinho, A.; \& Aversa, P. (2005). Sobre a experimentação da loucura no campo escolar. In COLI, F., \& Kupfer, M. (Orgs.). Travessias - inclusão escolar: a experiência do grupo ponte -Pré-escola Terapêutica Lugar de Vida. São Paulo: Caso do Psicólogo.

Cury, C. R. J. (2008). A educação escolar, a exclusão e seus destinatários. Educação em revista, n. 48, 205-222, Recuperado em 15 março, 2008, de http://www.scielo.br/scielo. php?script=sci_arttext\&pid=SO I 02-469820080002000 I 0\&lng=en\&nrm=iso.

Dubet, F. (2003). A escola e a exclusão. Cadernos de Pesquisa, 19, 29-45.

Estevão, I. R., \& Metzger, C. (20 16). Acompanhamento terapêutico: tática, estratégia e política. A peste, 7(2), 69-79.

Frigerio, G. (200 I ). Los bordes de lo escolar. In Duschatzky, S.: \& Birgin, A. Donde está la escuela? Ensayos sobre La gestión institucional em tiempos de turbulência. Buenos Aires: Flacso Manantial.

Kristeva, J. ( 1994). Estrangeiros para nós mesmos. Rio de Janeiro, Rocco.

Kupfer, M. C. M. (2005). Inclusão social: a igualdade e a diferença vistas pela psicanálise. In Kupfer, M. C. M., \& Colli, F. A. G. Travessias - inclusão escolar: a experiência do Grupo Ponte da Pré-escola Terapêutica Lugar de Vida. São Paulo: Casa do Psicólogo.

Kupfer, M. C. M., \& Petri, R. (2000). Por que ensinar a quem não aprende? Estilos da clínica.5(9), I09-I 17. Recuperado em 15 março, 2017, de http://pepsic.bvsalud.org/scielo. php?script=sci_arttext\&pid=S | 4 | 5-7 | 282000000200008\&lng=pt\&nrm=iso >.

Lacan, J. (1985). O Seminário. Livro 3: As psicoses. Rio de Janeiro: Jorge Zahar. (Trabalho original publicado em 1955-1956).

Lajonquière, L. de. (200I). Duas notas psicanalíticas sobre as crianças "com necessidades educativas especiais"..Proposições, 12,(2-3), 35-36. 
Marques, S. M. (2007). Pensar e agir na inclusão escolar de crianças com necessidades educacionais especiais decorrentes de uma deficiência: rupturas e mutações culturais na escola brasileira. Tese (doutorado em Educação). Faculdade de Educação da Univerdade de São Paulo, São Paulo, SP, Brasil.

Oury, j. (199|). Itinerários de formação. Revue Pratique, n. I, 42-50.

Patto, M. H. S. (2003). Passagens: a psicanálise em movimento. In Colli, F., \& Kupfer, M. C. (Orgs.). Travessias. São Paulo: Casa do Psicólogo.

Sereno, D. (2016). Acompanhamento terapêutico e educação inclusiva. Psychê. 10(18), |67-179.

Voltolini, R. (2005). A inclusão é não toda. In Kupfer, M. C. M., \& Colli, F. A. G Travessias inclusão escolar: a experiência do Grupo Ponte Pré-escola Terapêutica Lugar de Vida. São Paulo: Casa do Psicólogo.

(2004). Psicanálise e inclusão escolar: direito ou sintoma? Estilos da Clínica, 9(16), 92-101. Recuperado em 05 março, 2017, de http://pepsic.bvsalud.org/scielo. php?script=sci_arttext\&pid=S | 4 | 5-7 | 282004000 | 00009\&lng=pt\&tlng=pt. 